Ege Tıp Dergisi / Ege Journal of Medicine 2019; 58 (3): 195-199

\title{
Ventriküler destek cihazı takılan son dönem kalp yetmezliği hastalarında obezite ile artmış postoperatif komplikasyon gelişim riskinin ilişkisi
}

\author{
Correlation between obesity and increased postoperative complication risk in \\ end-stage heart failure patients who underwent ventricular assist device implantation \\ Pelin Öztürk ${ }^{1}$ Emre Demir ${ }^{2} \mathbb{B}$ \\ ${ }^{1}$ Ege Üniversitesi Tıp Fakültesi, Kalp ve Damar Cerrahisi Anabilim Dalı, İzmir, Türkiye \\ ${ }^{2}$ Ege Üniversitesi Tıp Fakültesi, Kardiyoloji Anabilim Dalı, İzmir Türkiye
}

Öz

Amaç: Ventriküler destek cihazı (VDC) uygulanan son dönem kalp yetmezliği (SDKY) olgularında obezite ile postoperatif komplikasyon sıklığı ilişkisinin incelenmesi.

Gereç ve Yöntem: Kliniğimizde SDKY tanısı ile devamlı akım sağlayan VDC implantasyonu uygulanan 373 hastanın kayıtları retrospektif olarak taranmıştır. Çalışmaya taranan komplikasyonlara yatkınlık yaratacak kontrolsüz metabolik hastalığı bulunmayan ve en az üç ay süreli takibi olan 167 olgu dahil edilmiştir. Demografik özelliklerin yanında uygulanan VDC tipi, son kontroldeki vücut kitle indeksi (VKI), vücut yüzey alanı (VYA) değerleri ile postoperatif major komplikasyonlardan yara yeri enfeksiyonu, pompa trombozu, gastrointestinal sistem (GIS) kanaması ve serebrovasküler olay (SVO) gelişimleri her olgu için kayıtlanmıştır. Hastaların VKİ ve VYA değerleri ile taranan komplikasyonların görülme sıklıkları istatistiksel olarak karşılaştırılmıştır.

Bulgular: Yirmisi (\%12) kadın, toplam 167 olgunun yaş ortalaması 53.3ะ13.1 (12-74) yıldı. Olguların 91 'inde (\%54.5) dilate, geri kalanlarda ise iskemik kardiyomiyopati tanısı mevcut olup, 117'sinde (\%70.1) HeartWare, 24'ünde (\%14.4) HeartMate-2 ve 26'sında (\%15.6) HeartMate-3 cihazı implante edilmiştir. Postoperatif ortalama $26.1 \pm 18.2$ aydaki son kontrolde ölçülen VKI ve VYA ortalaması $27.7 \pm 4.3$ ve $1.97 \pm 0.20 \mathrm{~m}^{2}$ idi. Tüm grupta yara yeri enfeksiyonu, pompa trombozu, GiS kanaması ve SVO sıklıkları sırasıyla \%22.8, \%21.0, \%15.0 ve \%15.6 olarak bulundu. Daha yüksek VKi'li olgularda pompa trombozu ve GiS kanaması görülme sıklığının artıı̆ı $(p=0.047$ ve $p=0.018)$, daha yüksek VYA olgularında da GiS kanaması görülme riskinin yükseldiği saptandı $(p=0.016)$. Ayrıca obezlerde GiS kanaması ve SVO riskinin yüksek olduğu bulundu $(p=0.012$ ve $p=0.040)$.

Sonuç: Kalp naklinde mortalite için ciddi risk faktörü olduğu bilinen obezite, transplantasyona köprüleme amaçlı VDC implantasyonu kararında da hasta seçiminde dikkat edilmesi gereken bir durumdur.

Anahtar Sözcükler: Obezite, postoperatif komplikasyon, ventriküler destek cihazı, vücut kitle indeksi

\section{Abstract}

Aim: Evaluation of the correlation between obesity and postoperative complication risk in end-stage heart failure (ESHF) patients who underwent ventricular assist device (VAD) implantation.

Materials and Methods: The charts of 373 ESHF patients underwent continuous-flow VAD implantation were reviewed retrospectively. One hundred-sixty-seven cases with minimum three months of postoperative follow-up were enrolled. Demographics and implanted VAD type, body mass index (BMI) and body surface area (BSA) that measured at the last follow-up visit as well as the presence of major postoperative complications including wound infection (WI), pump thrombosis (PT), gastrointestinal bleeding (GIB), and cerebrovascular event (CVE) were noted for each participant. Prevalence of the evaluated complications were statistically compared with both BMI and BSA scores.

\footnotetext{
Yazışma Adresi: Pelin Öztürk

Ege Üniversitesi Tıp Fakültesi, Kalp ve Damar Cerrahisi

Anabilim Dalı, İzmir, Türkiye

E-mail: pelin.ozturk@yahoo.com

Makalenin Geliş Tarihi: 25.03.2018 Kabul Tarihi: 05.04.2018
} 
Results: Of the 167 cases with a mean age of $53.3 \pm 13.1$ (12-74) years, 20 (12\%) were females. Implanted VAD type was HeartWare in 117 cases (70.1\%), HeartMate-2 in 24 cases (14.4\%), and HeartMate-3 in 26 cases (15.6\%). Mean follow-up, BMI and BSA scores were $26.1 \pm 18.2$ months, $27.7 \pm 4.3$ and $1.97 \pm 0.20 \mathrm{~m}^{2}$, respectively. Prevalence of WI, PT, GIB, and CVE were $22.8 \%, 21.0 \%$, $15.0 \%$, and $15.6 \%$, respectively. Increased $P T$ and GIB risks were found in cases with higher BMI $(p=0.047$ and $p=0.018$, respectively); and GIB risk was higher in subjects with greater $B S A(p=0.016)$. Obese patients had also higher risk for the development of both GIB and CVE $(p=0.012$ and $p=0.040$, respectively).

Conclusion: Obesity; which is a well-known risk factor for mortality in heart transplantation, may also be a predictive factor in deciding the optimal candidates for VAD implantation.

Keywords: Body mass index, obesity, postoperative complication, ventricular assist device.

\section{Giriş}

Son dönem kalp yetmezliği (SDKY) hastalarında yetersiz organ bağışı nedeniyle, giderek daha sık uygulanmaya başlanan ventriküler destek cihazı (VDC) implantasyonu, tüm dünyada ve ülkemizde başarıı şekilde uygulanmaktadır. Sıklıkla kalp transplantasyonuna köprüleme amaçlı uygulanan VDC implantasyonu, son yıllarda uzun dönem başarı oranlarının giderek arttığının bildirilmesiyle, çeşitli yazarlar tarafından kalp yetmezliği tedavisinde kalıcı tedavi yöntemi olarak nitelendirilmeye başlanmıştır $(1,2)$. Uzun soluklu ve pahalı bir tedavi yöntemi olmasının yanı sıra henüz kayda değer ve üzerinde fikir birliğine varılmış olan risk skorlaması bulunmaması nedeniyle, hastalara VDC implantasyonu kararı verilirken uzun dönem sonuçları kabul edilebilir olgular tercih edilmelidir (3). Obezitenin kalp transplantasyonu da dahil olmak üzere tüm kalp cerrahisi prosedürleri için yüksek risk faktörü olduğu bilinmektedir (4-6). Bu çalışmanın amacı, VDC uygulanan hastalarda obezitenin postoperatif dönemde gelişen major komplikasyonlarla ilişkisini ortaya koymak ve VDC implantasyonu için bir risk faktörü olduğunu göstermektir.

\section{Gereç ve Yöntem}

Kliniğimizde dilate veya iskemik kardiyomiyopati (KMP) sonrasında gelişen SDKY tanısı ile devamlı akım sağlayan VDC implantasyonu uygulanan 373 hastanın kayıtları retrospektif olarak taranmıştır. Çalışmaya halen hayatta olan, taranan komplikasyonlara yatkınlık yaratacak seviyede kontrolsüz metabolik hastalığı ya da onkolojik hastalığı bulunmayan ve en az 3 ay süreli takibi olan 167 olgu dahil edilmiştir. Çalışma Helsinki deklarasyonunda kabul edilen prensiplere uygun bir şekilde yürütülmüş olup, dahil edilen tüm katılımcılara uygulanan VDC implantasyonu cerrahisi öncesinde dosya kayıtlarına ulaşılarak çalışma yapılabileceği hakkında ayrıntılı bilgi verilmiş ve aydınlatıımış onam formu imzalatılmıştır.

Olguların demografik özelliklerin yanında implante edilen VDC tipi, son kontrol vizitlerinde ölçülen vücut kitle indeksi (VKI), vücut yüzey alanı (VYA) değerleri ile postoperatif dönemde görülebilen, morbidite ve mortalite üzerine doğrudan etkisi olabilecek ana komplikasyonlardan yara yeri enfeksiyonu, pompa trombozu, gastrointestinal sistem (GiS) kanaması ve serebrovaskuler olay (SVO) gelişimleri her olgu için kayıtlanmıştır. Hastaların VKI ve VYA değerleri ile postoperatif taranan komplikasyon görülme sıklıkları istatistiksel olarak karşılaştıııımıştır. Ayrıca Amerikan Ulusal Sağlık Enstitüsü kriterlerine (7) uygun olarak VKI değeri 30 ve üzeri olan olgular obez olarak kabul edilmiş ve obezite varlığında çalışılan komplikasyon gelişim risklerindeki artış varlığı istatistiksel olarak analiz edilmiştir.

Tüm VDC implantasyonu cerrahileri, genel anestezi altında ve kardiyopulmoner by-pass desteğinde uygulanmış olup, çalışma olgularına sürekli akım sağlayan HeartWare (HeartWare Inc, Framingmam, MA), HeartMate 2 (Thoratec Corp., Pleasanton, CA) ya da HeartMate 3 (St. Jude Medical Inc., St. Paul, $M N$ ) cihazından birisi implante edilmiştir. İmplante edilen üç farklı VDC tipine göre çalışma popülasyonunda alt grup değerlendirmeleri yapılmıştır.

Çalışma verileri SPSS 22.0 (IBM, Armonk, NY) yazılımı ile bilgisayar ortamına girildi. Verilerin düzgün dağılımlılığı Shapiro-Wilk testi kullanılarak belirlendikten sonra, ki-kare, ANOVA ve bağımsız değişkenler $t$ testleri kullanılarak istatistiksel analizler yapıldı; $p$ değerinin 0.05 'in altında olması istatistiksel olarak anlamlı olarak değerlendirdi. 


\section{Bulgular}

Çalışmaya alınan toplam 167 olgunun 20'si (\%12) kadın ve 147 'si (\%88) erkek olup, yaş ortalaması $53.3 \pm 13.1$ yıl (12-74 yıl) olarak bulundu. Olguların 91 'inde (\%54.5) dilate KMP, 76'sında (\%45.5) ise iskemik KMP tanısı mevcut olup, gelişen SDKY nedeniyle 117 olguda (\%70.1) HeartWare, 24 olguda (\%14.4) HeartMate 2 ve 26 olguda (\%15.6) HeartMate 3 cihazı implante edilmiştir. Tüm grup için postoperatif ortalama takip süresi $26.1 \pm 18.2$ ay (3-75 ay) olarak bulundu. Son takip vizitinde ölçülen VKİ ve VYA ortalaması çalışmaya dahil edilen tüm hastalar için sırasıyla $27.7 \pm 4.3$ ve $1.97 \pm 0.20 \mathrm{~m}^{2}$ olarak bulundu. Araştırmaya alınan postoperatif komplikasyonlar olan yara yeri enfeksiyonu, pompa trombozu, GiS kanaması ve SVO sıklıkları tüm çalışma grubu için sırasıyla \%22.8, $\% 21, \% 15$ ve \%15.6 olarak bulundu (Tablo-1).

Tüm çalışma popülasyonu dikkate alındığında, son takip vizitinde VKI değeri daha yüksek bulunan olgularda pompa trombozu ve Gis kanaması görülme sıklığının istatistiksel olarak arttığı (sırasıyla $p=0.047$ ve $p=0.018$ ), yara yeri enfeksiyonu ya $d a$ SVO gelişim riskinin ise değişmediği saptandı (sırasıyla $p=0.270$ ve $p=0.664$ ). Yine tüm çalışma grubu dikkate alındığında son takipte saptanan daha yüksek VYA değerleri ile Gis kanaması görülme riskinin istatistiksel olarak arttığı $(p=0.016)$, yara yeri enfeksiyonu, pompa trombozu ve SVO gelişim risklerinde ise istatistiksel anlamlı bir fark olmadığı görüldü (sırasıyla $p=0.513, p=0.139$ ve $\mathrm{p}=0.182$ ). Hesaplanan VKI değerinin 30 ve üzeri olması olarak nitelendirilen obezite, tüm olguların 45'inde (\%26.9) saptandı. Obez olgularda, VKI değeri 30'un altında saptananlar ile kıyaslandığında postoperatif dönemde GiS kanaması ve SVO riskinin yüksek olduğu saptandı (sırasıyla $p=0.012$ ve $p=0.040$ ).

Çalışma popülasyonu implante edilen VDC tipine göre yaş ve cinsiyet dağılımları açısından istatistiksel anlamlı fark bulunmayan (sırasıyla $p=0.152$ ve $p=0.077$ ) üç alt gruba ayrıldığında, yara yeri enfeksiyonu, pompa trombozu, Gis kanaması ve SVO gelişme sıklığı HeartWare cihazı implante edilenlerde sırasıyla \%23.1, \%23.1, \%15.4 ve \%19.7; HeartMate 2 cihazı implante edilenlerde sirasıly $\% 25, \% 25, \% 20.8$ ve $\% 8.3$; HeartMate 3 cihazı implante edilenlerde ise sırasıyla \%19.2, \%7.7, \%7.7 ve \%3.8 olarak bulundu. HeartMate 3 cihazı implante edilen hastalarda pompa trombozu, GiS kanaması ve SVO gelişme riskinin daha düşük olduğu fark edilmesine karşın, değerlendirmeye alınan dört komplikasyonun gelişim sıklığı açısından implante edilen cihaz tipine bağlı istatistiksel anlamlı fark saptanmadı (sırasıyla $p=0.878, p=0.191$, $p=0.418$ ve $p=0.076)$.

Tablo-1. Demografik Veriler ve Çalışılan Parametrelerin İmplante Edilen VAD Tipine Göre Değişimi.

\begin{tabular}{|c|c|c|c|c|}
\hline & $\begin{array}{c}\text { HeartWare } \\
(n=117)\end{array}$ & $\begin{array}{l}\text { HeartMate-2 } \\
\quad(n=24)\end{array}$ & $\begin{array}{l}\text { HeartMate-3 } \\
\qquad(n=26)\end{array}$ & $\begin{array}{l}\text { Toplam } \\
(n=167)\end{array}$ \\
\hline Cinsiyet-Kadın; n (\%) & $18(15.4)$ & $2(8.3)$ & - & $20(12)$ \\
\hline Yaş (yıl) & $53.0 \pm 14.3$ & $57.7 \pm 6.1$ & $50.8 \pm 11.3$ & $53.3 \pm 13.1$ \\
\hline \multicolumn{5}{|l|}{ Tanı; n (\%) } \\
\hline DKMP & $59(50.4)$ & $14(58.3)$ & $18(69.2)$ & $91(54.5)$ \\
\hline İKMP & $58(49.6)$ & $10(41.7)$ & $8(30.8)$ & $76(45.5)$ \\
\hline VKi & $27.2 \pm 4.2$ & $29.1 \pm 4.7$ & $28.6 \pm 3.6$ & $27.7 \pm 4.3$ \\
\hline VYA & $1.93 \pm 0.20$ & $2.05 \pm 0.18$ & $2.07 \pm 0.15$ & $1.97 \pm 0.20$ \\
\hline \multicolumn{5}{|l|}{ Komplikasyonlar; n (\%) } \\
\hline Yara yeri enfeksiyonu & $27(23.1)$ & $6(25)$ & $5(19.2)$ & $38(22.8)$ \\
\hline Pompa trombozu & $27(23.1)$ & $6(25)$ & $2(7.7)$ & $35(21)$ \\
\hline Gis kanaması & $18(15.4)$ & $5(20.8)$ & $2(7.7)$ & $25(15)$ \\
\hline SVO & $23(19.7)$ & $2(8.3)$ & $1(3.8)$ & $26(15.6)$ \\
\hline
\end{tabular}

DKMP: Dilate kardiyomiyopati, IKKMP: İskemik kardiyomiyopati, VKİ: Vücut kitle indeksi, VYA: Vücut yüzey alanı, Gís: Gastrointestinal sistem, SVO: Serebrovasküler olay. 


\section{Tartışma}

Günümüzde donör yetersizliği nedeniyle kullanım sıklığı giderek artan, ancak pahalı ve uzun soluklu bir tedavi şekli olan VDC implantasyonu için hasta seçiminin iyi yapılması, kısa ve uzun dönem izlemde görülebilecek major komplikasyonların sıklığını artıran risk faktörlerinin detaylıca belirlenmesi gerekmektedir (1-3). Literatürde birçok yayında obezite saptanan ya da VKI yüksek bulunan hastalarda VDC hastalarının uzun dönem sağkalımları üzerine etkili olabilecek birçok postoperatif dönem komplikasyonuna daha sık karşılaşıldığı bildirilerek, bu grup hastalarda hasta seçim kriterleri arasında obezitenin de girmesi gerekliliği tartışımıştır (4-6,8-15). Ancak tüm bu çalışmaların verilerine aykırı şekilde Natasya ve ark. (16) ise yaptıkları çalışmada obezitenin hem komplikasyonlar hem de mortalite üzerine herhangi bir etkisinin olmadığı bildirmişler ve yüksek VKI'nin VDC implantasyonu açısından bir kontendikasyon olarak tanımlanmaması gerektiğini savunmuşlardır.

Obez olarak tanımlanan yani VKI 30 ve üzeri olan olguların, literatürde yayınlanmış kalp cerrahisine ait verileri tarandığında, kalp transplantasyonu dahil olmak üzere tüm kardiyak prosedürlerde obezitenin postoperatif mortalite ve morbiditeyi arttırdığı görülmektedir (4-6). Brewer ve ark. (8) yaptığı çalışmada VDC implante edilen olgularının \%28'i obez olarak değerlendirilmiş olup, postoperatif dönemde bu olgularda mortalitede fark görülmediği ancak cihaz bağımlı komplikasyon ve rehospitalizasyon oranlarının istatistiksel anlamlı şekilde yüksek saptandığı bildirilmiştir. Go ve ark. (9) yapmış olduğu çalışmada da benzer şekilde VKI yüksek olguların postoperatif dönemde cerrahi revizyon gerektiren kanama ve SVO oranlarının anlamlı şekilde yüksek bulunmuştur (9). Bahsedilen bu çalışmalarda VKI'nin komplikasyonları arttırdığı bulgusunun tersine, mortalite açısından risk faktörü olmadığı belirtilirken, Musci ve ark. (10) tarafından yayımlanan çalışmada VKI 25 ile 29 arası olan hastaların postoperatif en iyi sonuçlara sahip olduğundan; 30 ve üzeri saptanan olguların ise erken dönem mortalite oranlarının yüksek bulunduğundan bahsedilmektedir. Bizim çalışmamızda da son takip viziti için hesaplanan VKi değerinin 30 ve üzeri olması olarak nitelendirilen obezite, tüm olguların \%26,9'unda saptanırken, VKI değeri 30'un altında saptananlar ile kıyaslandığında postoperatif dönemde GiS kanaması ve SVO riskinin literatürle uyumlu şekilde yüksek olduğu saptandı.

Hesaplanan VKI değerinin, VDC implantasyonu sonrası rastlanabilecek ve uzun dönemde sağkalım üzerine doğrudan tesiri bulunan major komplikasyonların görülme sıklığına etkisine bakılan çalışmamızda yara yeri enfeksiyonu ile VKI arasında istatistiksel olarak anlamlı bir fark bulunamazken, literatürde VKI yüksek hastalarda yara yeri enfeksiyonunun anlamlı şekilde arttığını ve bu olgularda hem ağızdan hem de intravenöz olacak şekilde uzamış antibiyotik kullanımı gerekliliği gösteren çalışmalar mevcuttur $(11,12)$. Çalışmamızda son takip vizitlerinde hesaplanan VKi değeri daha yüksek olan VDC implante edilmiş SDKY olgularında, pompa trombozu gelişim riskinin istatistiksel anlamlı şekilde yüksek olduğu saptanmıştır. Literatürde de benzer olarak, VDC implantasyonunun en ciddi komplikasyonlarından biri olan pompa trombozu gelişimi üzerine VKI değerinin etkisinin değerlendirildiği bazı çalışmalarda, VKI'nin artışına korele olarak tromboz riskinin arttığı bildirilmektedir $(9,13,14)$. Yine, konu ile ilgili olarak yapılan önceki çalışmalarda kadın cinsiyet ve ileri yaş ile birlikte postoperatif sağ kalp yetmezliği gelişimi ve von Willebrand faktör (VWF) eksikliği durumlarının VDC implantasyonu sonrası GiS kanama gelişimi açısından risk faktörü olduğu gösterilmiştir $(14,15)$. Çalışmamızda bu olgulardaki morbidite ve mortaliteyi etkileyebilen önemli bir komplikasyon olan GiS kanaması sıklı̆ı, hem VKi daha yüksek olan olgularda hem de VYA daha fazla olan olgularda ayrı ayrı olarak istatistiksel anlamlı şekilde yüksek bulunmuştur. Postoperatif takip döneminde bu olgular için ciddi morbidite ve mortalite sebebi olan komplikasyonlarından bir diğeri olan SVO gelişiminin VDC hastaları arasında görülme sıklığının araştıııldığı bir çalışmada, VKI değeri yüksek saptanan olgularda anlamlı şekilde yüksek oranda SVO görüldüğü bildirilmiştir (9). Bizim çalışmamızda VKI artışı ile SVO gelişim sıklığı arasında tüm hasta grubumuz için belirgin bir korelasyon gözlemlenmemekle birlikte, çalışma popülasyonumuzun hesaplanan VKİ değerinin 30 ve üzeri ile 30'un altı olarak ikiye ayrımasının ardından, obezite tanısı alan 45 olguda istatistiksel olarak anlamlı şekilde postoperatif dönemde SVO gelişiminin sık olduğu gözlemlenmiştir. 


\section{Sonuç}

Özellikle SDKY hastalarında sıklıkla görülen kardiyak kaşeksinin VDC implantasyonu ile düzelen dolaşımsal yetmezliğe ikincil olarak gerilemesi ile bu hastalarda hızlı kilo alımları görülebilmektedir. Çalışmamızda da ortaya konulduğu üzere obezite varlığının bu olgularda görülebilecek ciddi komplikasyonları ve sonuç olarak hasta sağkalımını etkilemesi nedeniyle VDC uygulanmış olguların kontrollerinde VKI hesaplamaları mutlaka yapılmalıdır. Hızlı kilo alımı gözlemlenen olguların diyetlerine dikkat etmeleri öğütlenmeli ve bu hasta grubunun takibinde özelleşmiş diyetisyenler ile düzenli görüşmeleri sağlanmalıdır. Ayrıca kalp naklinde mortalite için ciddi risk faktörü olduğu bilinen ve karar aşamasında rölatif kontendikasyonlar arasında kabul edilen obezite, transplantasyona köprüleme amaçlı uygulanacak VDC implantasyonu kararı esnasında da hasta seçiminde dikkat edilmesi gereken bir durum olarak değerlendirilmelidir.

\section{Kaynaklar}

1. Rose EA, Gelijns AC, Moskowitz AJ, et al. Long-term use of a left ventricular assist device for end stage heart failure. N Engl J Med 2001; 345 (20): 1435-43.

2. Fukunaga N, Rao V. Left ventricular assist device as destination therapy for end stage heart failure: The right time for the right patients. Curr Opin Cardiol 2018; 33 (2): 196-201.

3. Guha A, Nguyen D, Cruz-Solbes AS, et al. Risk stratification of patients with current generation continuous-flow left ventricular assist devices being bridged to heart transplantation. ASAIO J 2018; 64 (2): 196-202.

4. Pi-Sunyer FX. Medical hazards of obesity. Ann Intern Med 1993; 119 (7 Pt 2): 655-60.

5. Grady KL, Costanzo MR, Fischer S, Koch D. Preoperative obesity is associated with decreased survival after heart transplantation. J Heart Lung Transplant 1996; 15 (9): 863-71.

6. Filardo G, Pollock BD, Edgerton J. Categorizing body mass index biases assessment of the association with postcoronary artery bypass graft mortality. Eur J Cardiothorac Surg 2017; 52 (5): 924-9.

7. Clinical guidelines on the identification, evaluation, and treatment of overweight and obesity in adults: The evidence report. Obes Res 1998; 6 (Suppl 2): 51S-209S.

8. Brewer RJ, Lanfear DE, Sai-Sudhakar CB, et al. Extremes of body mass index do not impact mid-term survival after continuous-flow left ventricular assist device implantation. J Heart Lung Transplant 2012; 31 (2): 167-72.

9. Go PH, Nemeh HW, Borgi J, Paone G, Morgan JA. Effect of body mass index on outcomes in left ventricular assist device recipients. J Card Surg 2016; 31 (4): 242-7.

10. Musci M, Loforte A, Potapov EV, et al. Body mass index and outcome after ventricular assist device placement. Ann Thorac Surg 2008; 86 (4): 1236-42.

11. Raymond AL, Kfoury AG, Bishop CJ, et al. Obesity and left ventricular assist device driveline exit site infection. ASAIO J 2010; 56 (1): 57-60.

12. Clerkin KJ, Naka Y, Mancini DM, Colombo PC, Topkara VK. The Impact of obesity on patients bridged to transplantation with continuous-flow left ventricular assist devices. JACC Heart Fail 2016;4(10):761-8.

13. Han JJ, Sooppan R, Johnson AP, et al. Higher body mass index increases risk of HeartMate II pump thrombosis but does not adversely affect long-term survival. Circ J 2017; 81 (2): 213-9.

14. Boyle AJ, Jorde UP, Sun B, et al. Pre-operative risk factors of bleeding and stroke during left ventricular assist device support: An analysis of more than 900 HeartMate II outpatients. J Am Coll Cardiol 2014; 63 (9): 880-8.

15. Balcioglu O, Kemal HS, Ertugay S, et al. Risk Factors of Gastrointestinal Bleeding After Continuous Flow Left Ventricular Assist Device. ASAIO J 2017 Sep 27. doi: 10.1097/MAT.0000000000000678. [Epub ahead of print]

16. Volkovicher N, Kurihara C, Critsinelis A, et al. Effect of obesity on outcomes in patients undergoing implantation of continuous-flow left ventricular assist devices. J Artif Organs 2018 Jan 25. doi: 10.1007/s10047-017-1013-2. [Epub ahead of print]. 